\title{
Progress, problems and prospects for standardization of greenhouse-related technologies
}

\author{
Yanzhao Ren ${ }^{1,2}$, Minjuan Wang ${ }^{1,2}$, Iftikhar Ahmed Saeeda ${ }^{1,2}$, Xuerui Chen ${ }^{1,2}$, Wanlin Gao ${ }^{1,2^{*}}$ \\ (1. College of Information and Electrical Engineering, China Agricultural University, Beijing 100083, China; \\ 2. Key Laboratory of Agricultural Informationization and Standardization, Ministry of Agriculture, Beijing 100083, China)
}

\begin{abstract}
In recent years, the scale of greenhouse grows rapidly and steadily in China, which promotes the development of greenhouse technology and the demand for standardized technology. However, the standardization process of greenhouse industry in China has been facing with the problem of unbalanced development with the practical standard system for many years. To solve these problems, the most characteristic greenhouse designs used in China contributing to this work are presented in detail. And the development of standard system and the standardization efforts of them are summarized and analyzed in relationship to the data presented in this paper. In this way the origin of greenhouse standard system in China and context of the system development and standardization of greenhouse structure are clarified. It was also found that the development and iterative update of greenhouse standard system are under the influences of enterprises which as the participation of standard constitutors were proved to play an important role in promoting the standardization development of greenhouse. The outcome of this work may be utilized to perfect the greenhouse standardization system and improve the greenhouse standardization efficiency that dominate the facility agriculture in China.
\end{abstract}

Keywords: greenhouse, standardization, standard system, informationization, greenhouse technology DOI: $10.25165 /$ j.ijabe.20181101.3857

Citation: Ren Y Z, Wang M J, Saeeda I A, Chen X R, Gao W L. Progress, problems and prospects for standardization of greenhouse-related technologies. Int J Agric \& Biol Eng, 2018; 11(1): 40-48.

\section{Introduction}

The greenhouse is designed to reduce the dependence of agricultural production on the natural environment, and apply the land potential productivity to improve the efficiency of agricultural production by means of modern technology, machinery and management, and also to provide relatively controlled illumination, temperature, moisture and other environmental conditions for agricultural industry ${ }^{[1,2]}$. In recent years, the scale of greenhouse grows rapidly and steadily in China. In 2015, the greenhouse joint meeting reported that the proportion of greenhouse in China had reached 4.109 million $\mathrm{hm}^{2}$. Since 2010, the annual growth rate of it has exceeded $12 \%$. The rapid growth in greenhouse scale promotes greenhouse technology developments and the demand for standardized technology. The greenhouse standardization process is developing and approving upon technical standards. Specific standards are worked out by experiments and observations; hence the standardization is a tool in the quality control process. Therefore, the degree of perfection and

Received date: 2016-12-14 Accepted date: 2017-07-28

Biographies: Yanzhao Ren, $\mathrm{PhD}$, research interests: agricultural electrification and automation, Email: xiaozhaochina@163.com; Minjuan Wang, PhD, Post-doctoral fellow, research interests: plant factory and environmental science, Email: minjuan@cau.edu.cn; Iftikhar Ahmed Saeeda, $\mathrm{PhD}$, research interests: precision agriculture, IoT and proximal sensors, Email: ias_dr@hotmail.com; Xuerui Chen, $\mathrm{PhD}$, research interests: Agricultural information management, Email: chenxueruiabc@163.com.

*Corresponding author: Wanlin Gao, $\mathrm{PhD}$, Professor, research interest: agricultural informationization and application specific chip. College of Information and Electrical Engineering, China Agricultural University, Beijing 100083, China. Tel: +86-10-62738535; Email: gaowlin@cau.edu.cn. generality of standard system of greenhouse should receive attention, even though some studies showed that those standards could not be wholly applied to every country ${ }^{[3,4]}$. The design of such structures should be guided by European standard for greenhouse construction, but an extended tendency of cultivators to import standard foreign commercial greenhouses with doubtable official approval and structural adequacy seems to be a common phenomenon in many cases ${ }^{[4-7]}$. It also proves that the implementation of greenhouse standards is objectively affected by the environment. This should be accredited to the reason that the standard system of greenhouse and the greenhouse application demand does not match. Some scholars from different fields in western countries and in China have done the research on the labor standards for different plants growing in greenhouse in different environments ${ }^{[1,8]}$. The range of standards covers plant management, environmental maintenance, etc. In theory, greenhouse indoor environment should be consistent and free from the external environment but the greenhouse environment is not completely isolated from the external environment, and greenhouse technology also affects the greenhouse internal environment control level simultaneously. In this way, the standardization efforts have attracted a lot of research resources. Especially in China, there are many types of greenhouses due to the complex environments. If the standardization of greenhouse structure is backward, it will lead to a multifarious and redundant agricultural standard system of greenhouse agronomy to be built. Therefore, greenhouse structure standards and greenhouse agronomic criteria should be analyzed together to observe the balance of their development.

This paper focuses on the significant progress that has been made in greenhouse standardization over the years since the first compulsive standard about greenhouse technic named 
'GB4176-1984 agricultural plastic shed prefabricated steel skeleton' was completed published in $1978^{[49]}$. In the past and particularly in the 'greenhouse promotion period' driven by government agencies, the primary focus on greenhouse agronomic standard was on the operation of greenhouse crops. Many greenhouse agronomic standards remain classified and cannot be discussed in detail within this paper. However, in recent years, it has been recognized that greenhouse structure standard could severely impact on development of greenhouse industry ${ }^{[9]}$. Many types of greenhouse as the agriculture infrastructure, for example, single greenhouse cover a large geographical area, as does the Venlo greenhouse introduced from aboard. However, the large coverage area of them leads to an increased likelihood of hidden danger and maintenance cost, with the potential of inducing complex use requirements and maintenance habits, to facility agricultural production ${ }^{[10,11]}$. There also appears to be a new impetus in the greenhouse sector to consider unifying the standard system for that greenhouse technology develops rapidly and enterprise participation increases. Recently, much effort has been expended on producing greenhouse agronomic standard and updating greenhouse facility standard for guidance to the greenhouse producer and maintainer. This study discusses the progress in greenhouse standardization efforts and an overview of greenhouse standardization system into greenhouse type, standard content and standard level.

\section{Greenhouse structures}

\subsection{Single span greenhouse}

\subsubsection{Low tunnels}

Low tunnels covered with clear plastic agricultural film can produce high quality fruit with low disease incidence though the winter in many locations. Therefor it plays an important role in protected cultivation systems ${ }^{[12]}$. Low tunnels are more appealing as a potential selection for seasonal use demand, because other greenhouse construction and repair require greater expense and labor ${ }^{[13]}$. Their typical dimensions are shown in Figure 1a. The structure of low tunnels mainly includes a semi-cylindrical supporting framework, plastic film coverings and string or wire which keeps the film in place. The frameworks which made by wood, bamboo, concrete or steel are secured into ground at a reasonable spacing which ranges from $1.5 \mathrm{~m}$ to $2 \mathrm{~m}$. The plastic film is stretched over the arches and buried into the ground along the sides. The film can be lifted between the supporting arch and the retaining wire on both sides for ventilation.

\subsubsection{Round-arched tunnel greenhouses}

Round-arched tunnel greenhouse (Tunnel greenhouses) are used in the north and the south of China, in which the southern parts use sunshade rainproof and limited heat preservation as a mainstream greenhouse. Figure $1 \mathrm{~b}$ shows the dimensions of two typical tunnels. The frame material can be made of bamboo, wood, concrete, galvanized steel tubes or galvanized steel plate. Some tubes and wires are used to stabilize the structure in the longitudinal direction. The most important advantage of the single-span tunnels is the relatively simple construction system and its good wind resistance.

\subsubsection{Solar greenhouses}

Solar greenhouse, which is the result of the application of new technology and new material, adopt the ban type structure, and the shaded surface is bearing wall which can store energy and preserve heat. Figures $1 \mathrm{c}$ and $1 \mathrm{~d}$ show the dimensions of solar greenhouse. This type of structure work with heat preservation quilt or other thermal insulation material can well meet the demand of the temperature of the greenhouse production in winter in the north of China.

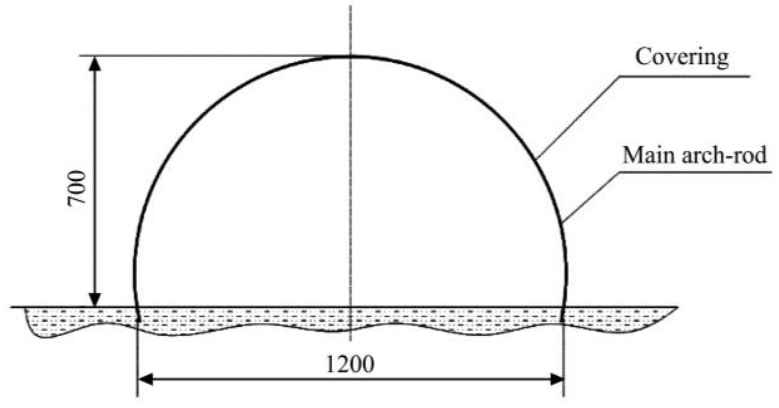

a. Low tunnel greenhouse

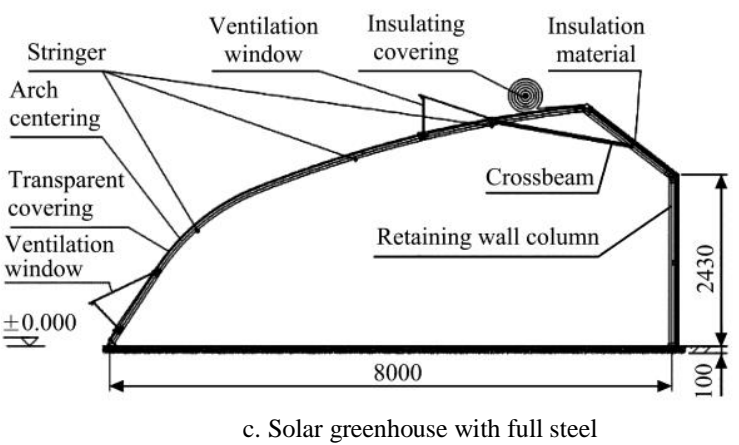

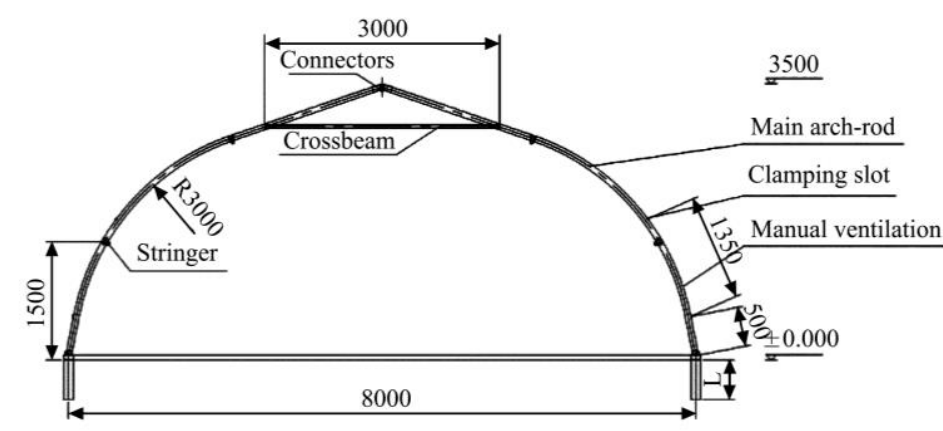

b. Round-arched tunnel greenhouse

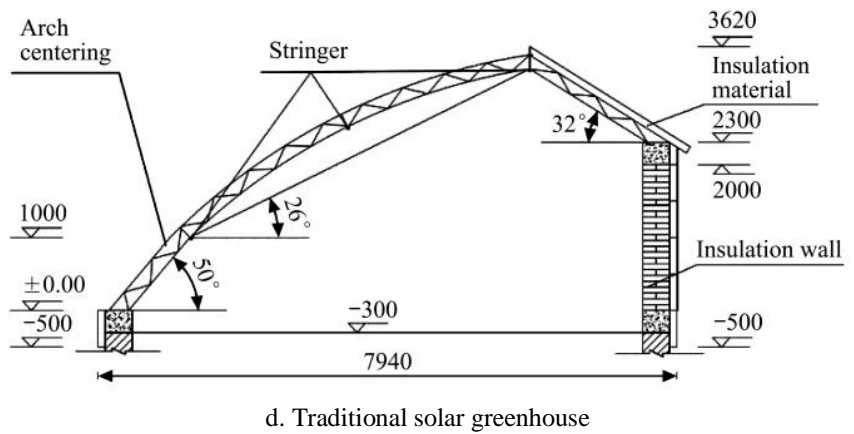

d. Traditional solar greenhouse

\subsection{Multi-span greenhouse}

The structural features of the multi-span greenhouse which are the development trend of modern large-scale greenhouse technology are that a high and large span structure is constituted by the same structure unit through the roof gutter or other structure. This structure is advantageous to realize intelligent greenhouse automation, scale, and production management, and further increase the efficiency of the land productivity ${ }^{[53]}$. It consists of a 
structure covered by multiple small-pitched roofs of $3.2 \mathrm{~m}, 3.6 \mathrm{~m}$ or $4 \mathrm{~m}$ span. They are built in continuous big blocks covering a total ground area of 1-2 $\mathrm{hm}^{2}$ per grower (average area of newly built greenhouses).

\subsubsection{Venlo-type greenhouse}

The Venlo-type greenhouse, is the most popular greenhouse type in the Netherlands, and it was introduced into China from Holland, Japan and Israel between 1979 and 2004 ${ }^{[14]}$. Its typical structure is shown in Figure 2a. The roof of Venlo-type construction is supported by columns, placed under each gutter, or one under every second or third gutter. Venlo-type greenhouses are standardized to a large degree, and there for their construction is maintainable and cheaper ${ }^{[15]}$. The standard Venlo type greenhouse structure unit is mainly composed of two parts, one includes span plane truss, column and roof within the span ranges, and the other is consisted of trellis girders (trusses) and gutters out of the span ranges. Trusses are mounted on greenhouse columns, and the roof installed in the greenhouse through the gutter or truss column. The foundation of a greenhouse column mostly consists of a pre-fabricated concrete pole cast in a concrete block at a certain depth below the surface ${ }^{[16-18]}$.

\subsubsection{Wide-span greenhouses}

Figure $2 b$ shows a wide-span greenhouse. These greenhouse types can be built as single span or multi-span structures, where neighboring spans are connected along the gutter. The span width varies between 6-15 $\mathrm{m}^{[17]}$.

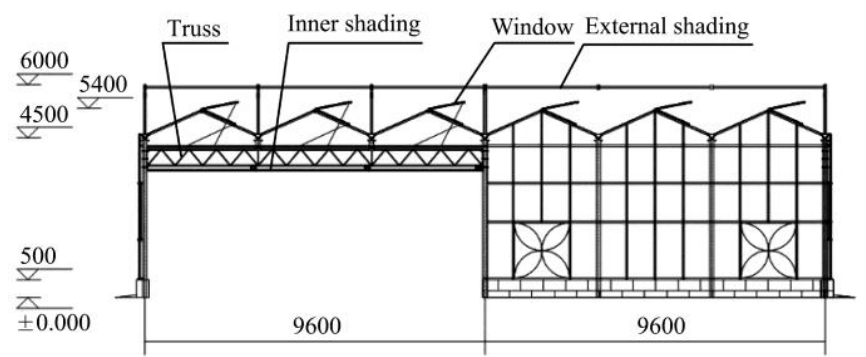

a. Venlo-type greenhouse

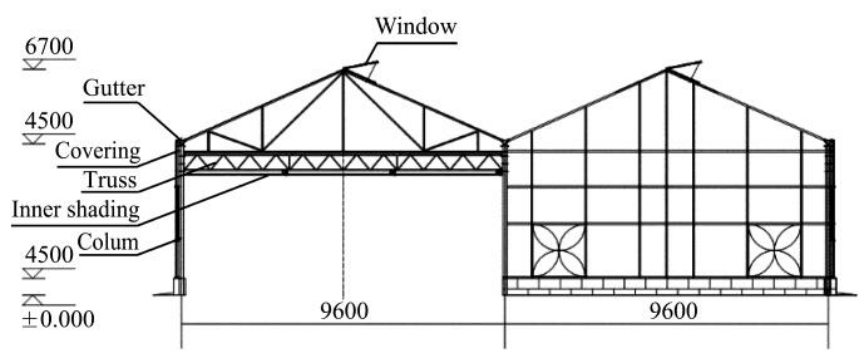

b. Wide-span greenhouse

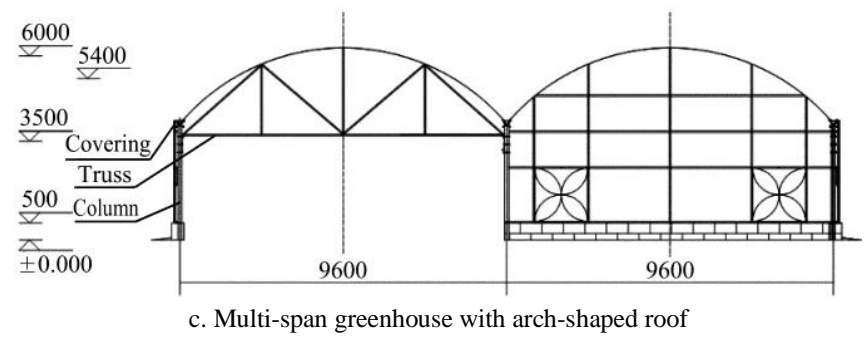

Figure 2 Multi-span greenhouse (All dimensions are in $\mathrm{mm}$ )

\subsubsection{Multi-span greenhouse with arch-shaped roof}

Many type of multi-span greenhouse with arch-shaped roof are built around the world, and it also has many kinds of derivatives ${ }^{[19,20]}$. The framework are made of timber, bamboo, PVC pipe, galvanized steel pipe, concrete, galvanized steel pipe or galvanized steel sheet. The covering is usually consisted of plastic film or polycarbonate board ${ }^{[21]}$. The shape of the roof is either a round arch or a Gothic arch shape roof. The Gothic arch type has better roof drainage performance and anti-condensation performance compared with the round $\operatorname{arch}^{[23,24,48]}$. The main structure is shown in Figure 2c.

\section{Greenhouse standardization degree}

Most of the multi-span greenhouse using light steel structure in the world ${ }^{[14,25]}$. With the development of material technology, the small section steel structure has gradually replaced other materials in the frame of arched greenhouse and solar greenhouse ${ }^{[26]}$. The greenhouse is a comprehensive facility with properties of construction and mechanical products ${ }^{[24]}$. In the process of standardization of machinery and construction industry, it is very important for the popularization of the corresponding structural technology to organize the design of various structural component standards. Therefore, the greenhouse can also gradually increase the level of standardization through the standard design of structural parts and building materials. The method of measuring the degree of greenhouse standardization can be referenced to the standardized factor measurement method of the machinery industry.

\subsection{Standardized coefficient}

Standardization coefficient is the index to evaluate the degree of product standardization. It is a parameter that measures the degree of standardization and generalization of a product ${ }^{[27,50,51]}$. The standardized coefficient is the sum of the product standard component coefficient $\left(R_{b}\right)$, the coefficient of purchased parts $\left(R_{w}\right)$, the coefficient of the borrowed parts and the coefficient of the common parts $\left(R_{t}\right)$. It can be calculated according to the number of component $\left(R_{j}\right.$, Equation (1)) and the number of varieties $\left(K_{z}\right.$, Equation (2) $)^{[51]}$.

$$
\begin{aligned}
& R_{j}=R_{B}+R_{T}+R_{W}=\frac{\sum B_{j}+\sum T_{j}+\sum W_{j}}{\sum J} \times 100 \% \\
& K_{j}=K_{B}+K_{T}+K_{W}=\frac{\sum B_{z}+\sum T_{z}+\sum W_{z}}{\sum Z} \times 100 \%
\end{aligned}
$$

where, $B$ represents the standard parts, components, and parts of the product; $T$ represents the general parts, components, and parts of the product; $W$ represents the borrowed parts and the purchased parts, components, and parts of the product; $J$ represents the total number of versions; $Z$ indicates the total number of species.

\subsection{Calculation principle}

The basis for calculating the product standardization factor is the statistical calculation of the number of parts of a product. In order to make the product standardization coefficient calculated by the objective reality, in the process of product parts statistical calculation process the following principles should be followed: the greenhouse should be in the same size; the representative model is the latest in its kind.

\subsection{Calculation results}

The standardized coefficient calculation results according to the above calculation method are shown in Table 1. As the greenhouse steel structure is a trend, and cold bending steel structure in the construction industry application maturity is higher, we choose the latest type of cold bending structure greenhouse as a calculation sample ${ }^{[28,52]}$. The greenhouse structure uses a large number of standard fasteners, which are more than 5 times the number of greenhouse components. Standard fasteners are not included in the standardized parameters to reflect the degree of 
standardization of greenhouse structure.

Table 1 Standardized parameters of greenhouses

\begin{tabular}{cllccc}
\hline Greenhouse type & Parameter class & $B / \%$ & $T / \%$ & $W / \%$ & $J / \%$ \\
\hline \multirow{2}{*}{ Tunnel greenhouse } & Varieties $(K)$ & 47.95 & 3.57 & 0.51 & 52.03 \\
& Components $(R)$ & 24.40 & 12.3 & 4.85 & 41.55 \\
\hline \multirow{2}{*}{ Solar greenhouse } & Varieties $(K)$ & 72.94 & 0.30 & 5.09 & 78.33 \\
& Components $(R)$ & 12.50 & 0.00 & 15.06 & 28.12 \\
\hline \multirow{2}{*}{$\begin{array}{c}\text { Venlo-type } \\
\text { greenhouse }\end{array}$} & Varieties $(K)$ & 74.05 & 4.68 & 20.22 & 98.96 \\
\hline
\end{tabular}

\section{Greenhouse standards}

The greenhouse standardization process is developing and approving upon technical standards. Specific standards are worked out by experiments and observations; hence standardization is a tool in the quality control process. Recently, the studies of greenhouse standardization focus on the following two aspects: one is the greenhouse structure standards; the other is greenhouse production standards. For the first one, there are many different categories of greenhouse, including single tunnel greenhouse, solar greenhouse, and multi-span greenhouse, are developing through the optimization of greenhouse structure and the introducing of new types of greenhouses. In accordance with those, the requirements for different ecological types and climatic conditions can be fulfilled $^{[28-30]}$. For the second aspects, some scholars from different fields in Western countries and in China have done the research on the labor standards for different plants grow in greenhouse in different environments ${ }^{[22,31,32]}$. In China, there are also complex environments and many types of greenhouses. If the standardization of greenhouse structure is backward, a load of agronomic standardization points at greenhouse plants will magnify exponentially. Therefore, greenhouse structure standards and greenhouse agronomic criteria should be analyzed together to observe the balance of their development ${ }^{[33]}$.

In 2012, the National Greenhouse Development '12th Five-Year' Plan stated that: complete standardization system had not been developed in China due to the fact that the related technology of greenhouse belongs to the interdisciplinary subject and other factors. The orderly development of Greenhouse specification was limited by reason that the requirement for the rapid expansion of greenhouse could not be met by the standard punished at that time ${ }^{[34]}$. There are various standards of the greenhouse production, 3 items are upcoming, 17 items are invalid by the year 2016 from 1984 in which the first one was developed which was named 'GB4176-1984 Agricultural plastic casing fabricated steel skeleton'. The cover area of greenhouse depends upon building material. It has covered the each aspect of greenhouse and ran through the whole life cycle of the greenhouse. The variation trend of kinds and number of the related technical standards can explain that the priorities and constraints in the process of greenhouse development. And the development of greenhouse represents and affects the level and developing a speed of the greenhouse technology.

\subsection{Greenhouse standard distribution}

\subsubsection{Distribution from greenhouse types}

As depicted in Figure 3a, from 2008 to 2015, solar greenhouse related standard has an average annual growth of 34 standards, the plastic shed has increased annually 15 versions, and that of the multi-span greenhouse is 3.4 ones. It is easy to prove that solar greenhouse related standards grow most rapidly than the other two kinds of the greenhouse, and that of the multi-span greenhouse is relatively slow. The state of the development of the three type of greenhouse is in line with the actual usage of our greenhouse. A solar greenhouse is working diffusely in the in northern China; it has the special structural features which include excellent heat preservation performance, low requirements for land area and so on With the rapid development of steel structure technology, the solar greenhouse structure has experienced the soil-wood form, soil-bamboo form, soil-steel form to the developing of the whole cold bending light steel structure. The plastic tunnel has a bigger areal distribution than solar greenhouse for the base that it is used all regions in China. The application of it is temporary and seasonal, and it will be assembled and disassembled frequently compared with other two types. There are not heavy equipment installation requirements for its framework. The lower level of technical and practical demand leads to the slower development of tunnel greenhouse than that of the solar greenhouse. The formulation of the standard of multi-span greenhouse mainly referred to the international standards because these depend upon imported technology ${ }^{[54,55]}$. The related technic of it has been being localized and standardized since the development of greenhouse was promoted actively by the government. In the past several years, this type expanded little slower because it requires capital, land, and technology issues and Chinese farmers cannot support. This type of greenhouse has the greater potential for development according to the country's new agricultural development strategy and with other particular advantages. It has high space, suitable for mass production and easy to maintain.

4.1.2 Distribution from standards hierarchy

The national standards are published by the national standard organization. Industry (group) standard is considered and issued by the industry standardization organizations or institutions. Local standards are released by some parts of the country. Enterprise standards work within the scope of the enterprise. There are two kinds of the use of standard with the decrease of the using range, one kind is complementing the existing national standards as the minimum standard in general, and the other kind is taking relevant standards made by a local corporation, industry, and enterprise as a supplement of national standards when it is in existence.

By analyzing the data in Figure $3 b$, we can find that there are 5 national standards, 43 industrial standards and 396 local standards in March 2016. The growth rate of the standard beyond to different range of application is shown in the Figure 8. After 2008 the industry and the local standard have been increased tremendously. The average speed of growth of them is 3.1 versions and 43.4 versions per annum, and one of national standards and enterprise standards is 0.1 versions and 0.2 versions. In greenhouse related standards in China, national standards and enterprise standards growth rate is extremely low and local standards and industry standards have an oppositely high processing speed.

\subsubsection{Distribution from technical object}

During the process of greenhouse production application, there are three dimensions of standardization, which is greenhouse structure standard, greenhouse production technology standard and product standard. The greenhouse structure standard, which mainly involves the greenhouse structure planning, design, construction, management, maintenance, etc., is not only covered greenhouse main structure itself, also includes greenhouse ancillary production equipment. Greenhouse has special construction for the case that it has some characters that make the standard of it 


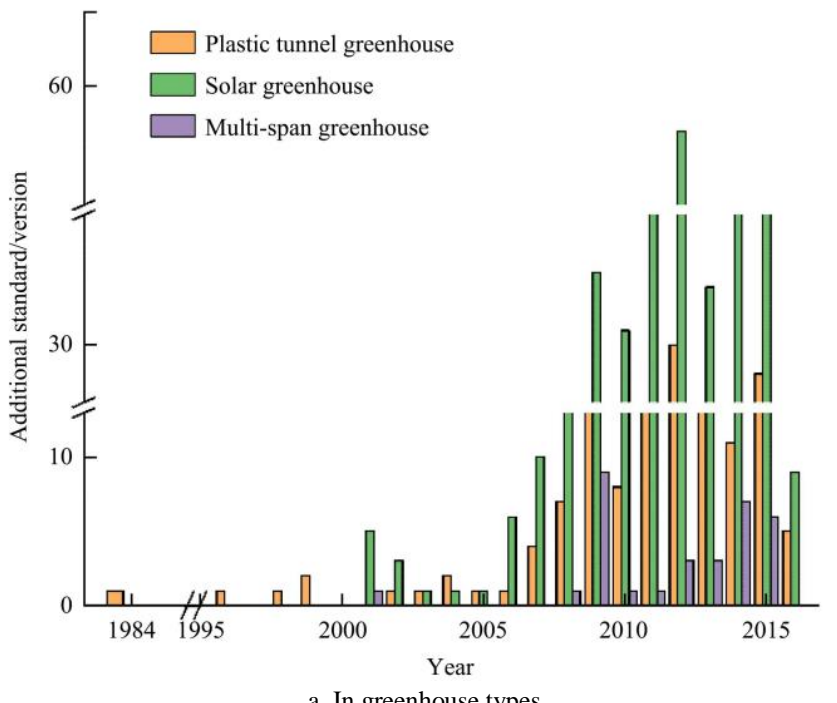

a. In greenhouse types
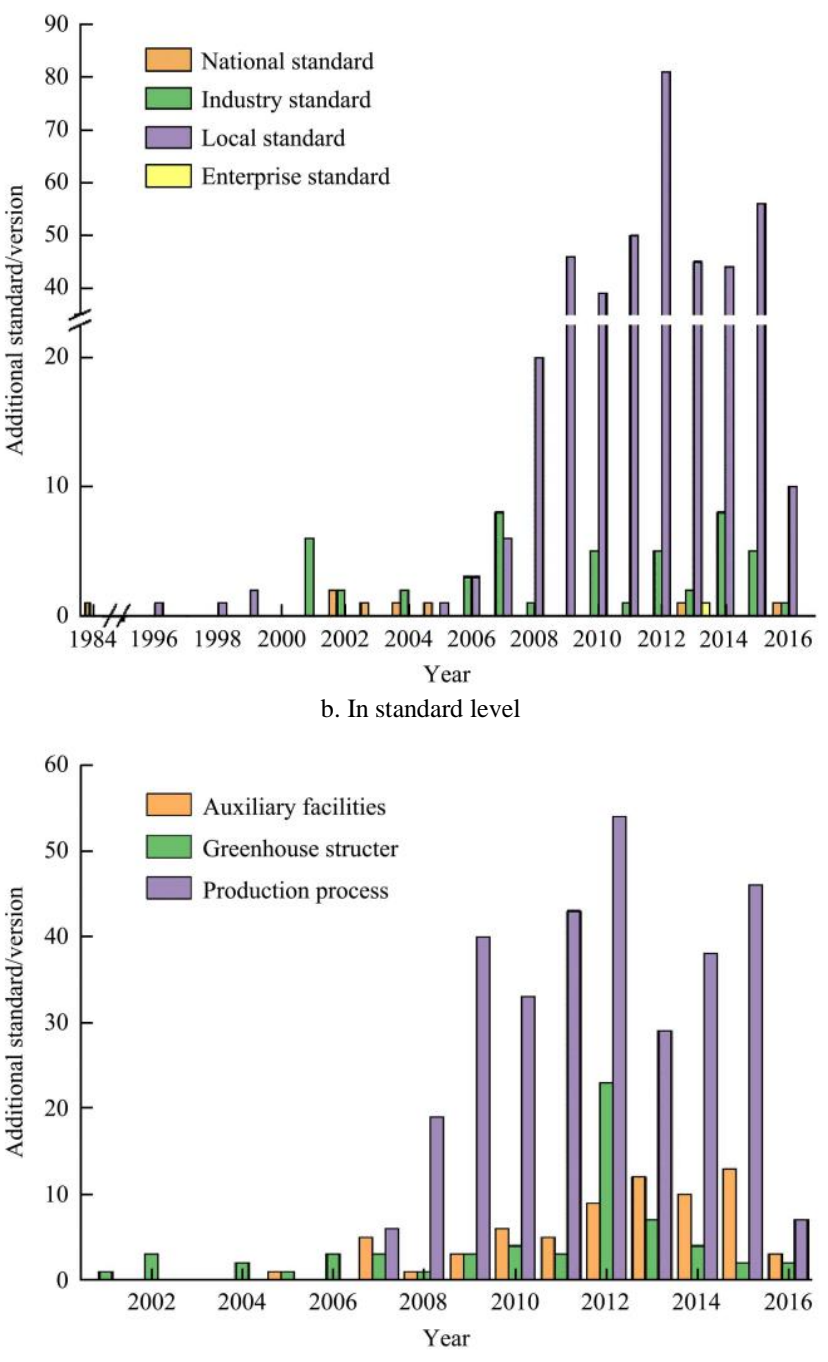

c. In technical content

Figure 3 Annual growth data analysis of greenhouse standard

different from that of common building. It has a high degree of mechanization, a simple structure, and higher requirements for economy. Greenhouse production technology standard mainly aims at greenhouse interior production technology procedures. The form of the main usage of greenhouse in China is the household contract responsibility system, as a result the indoor production efficiency depends on the operator's experience. A product standard refers to the greenhouse production product quality standards. The function of product standards is to regulate greenhouse product quality management, change agriculture development from extensive mode which shows indifference to quality, and the way of using the new production technology with the old manufacturing philosophy ${ }^{[4,7,16]}$.

There are about 131 active standards is related to greenhouse construction, 314 versions are working on greenhouse production process, and no standard of greenhouse products is observed until in March 2016. As is showed in Figure 3c, the annual growth rate of related active standards of greenhouse production process appeared firstly in 2007, but the first standard of greenhouse structure is found in 2001. The standard specification of fields all had a high speed of growth since 2008 to 2015. Greenhouse production process related standards grow by an average of 34.2 versions, greenhouse structure standards has a growth with an average of 12.4 versions range from 2008 to 2015 .

The scope of greenhouse production process related standard has a simple structure which is mainly related to crops in greenhouse cultivation practices; coverage of the greenhouse structure related standard structure contains auxiliary management and greenhouse structure. Auxiliary management mainly includes greenhouse ancillary equipment and maintenance management standards that are mainly used to standardize the use and maintenance of greenhouse production. Greenhouse structure mainly includes the structural design and construction of the greenhouse. It is mainly used to standardize management of the greenhouse structure of related technical specification. Greenhouse structure related standards are more able to reflect the greenhouse technology innovation and development ${ }^{[5,35-37]}$. As of March 2016, there is a total of 68 greenhouse auxiliary management related standards and 62 greenhouse institutions related standards. Greenhouse auxiliary management standards grew by an average annual increase of 7.3 versions, greenhouse structure standards grew by an average annual growth of 5.8 versions. Based on the analysis of greenhouse production data technology standard, greenhouse structure related standards has the slowest growth rate, and also have the fewest number of standard.

4.1.4 Distribution from technical content and greenhouse type

A greenhouse can be used for melons, fruits and flowers planting industry, nursery and many other types of agricultural production. In China, about $86 \%$ of active standards of greenhouse point to the standardized process of production, and those of them are mainly fit for a solar greenhouse as shown in Figure 4a.

4.1.5 Distribution from standards hierarchy and greenhouse type

The data analysis from the Figure $4 \mathrm{~b}$ shows that the share of enterprise standard, which as the most important standard executive's participation in the greenhouse system is almost zero ${ }^{[49]}$.

\subsection{Progress of revising greenhouse standard}

Standard repeal is divided into two cases, one is the national standards, industry standards, and local standards are eradicated for meet the need of economic construction and development of science and technology, and those should be supplemented with enterprise standards in this field; the other one is the old one is invalided because it is replaced by the new one which is established according to the needs of the actual economic construction and prepare by the responsible department or unit. In general, the first situation described referred to that the standards have been eliminated and no longer allowed to be used; in the second case, standard items appear technology upgrading, part of standard is vicious $^{[3,38]}$. 
By 2016, 17 greenhouse standards were abolished, and the overall trend is shown in Table 2 below. Combined with the aforesaid, the number of amendment and revocation of greenhouse standard from 2010 to 2014 revision and abolishment makes up $82 \%$ of the whole revised and abolished ones so far. In 2012, the percentage is even 35.3. Now about $59.2 \%$ of criterion made

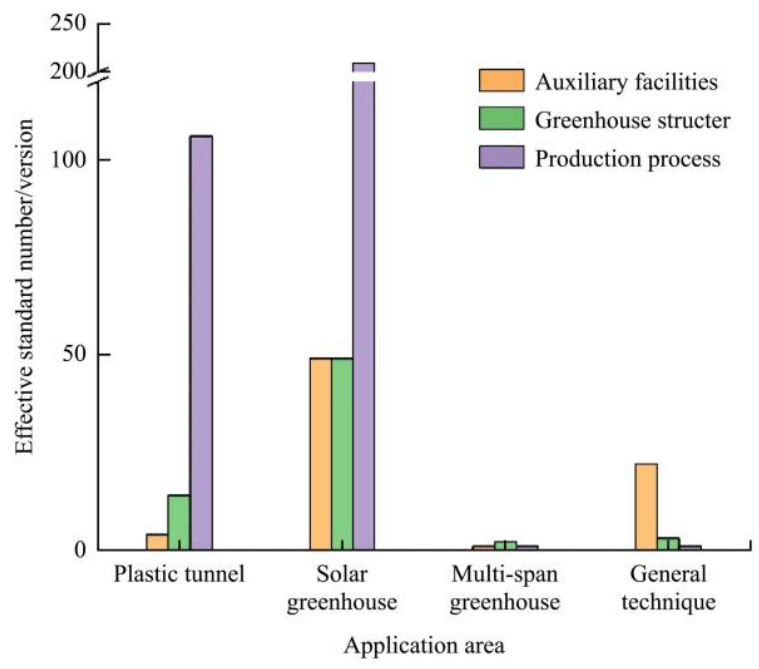

a. Greenhouse types and technical content before 2006 are modified or rescissory. The trends have changed that only one was terminated which were formulated after 2008 , and no amendment among those. It shows that a wide range of updates of a greenhouse related technologies has been appearing on which the representation is the iteration of greenhouse standard along with the greenhouse development peak.

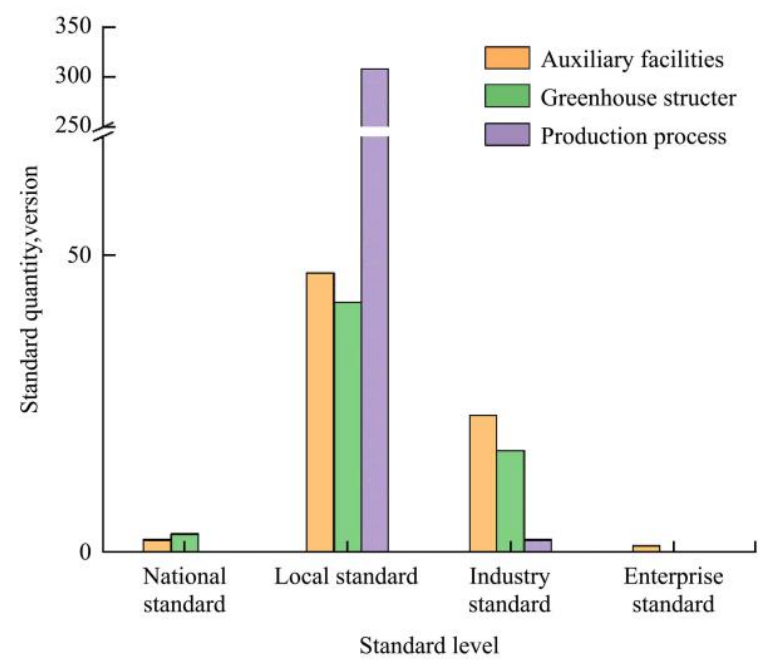

b. Standard level and technical content

Figure 4 Cross analysis of greenhouse standard data

Table 2 Information about revelatory standards and corresponding replacement

\begin{tabular}{|c|c|c|}
\hline Abolish standard No. & Name of the abolition standard & An alternative standard No. \\
\hline GB4176-1984 & Agricultural plastic casing fabricated steel skeleton & NY/T7-1984 \\
\hline DB23/T447-1996 & Plastic greenhouse cucumber cultivation technology procedures & DB23/T447-2011 \\
\hline DB62/T557-1998 & Qingyang sweet cherry dwarf greenhouse cultivation technical specifications & DB62/T557-2012 \\
\hline DB22/T1501.7-1999 & Pollution-free agricultural products plastic paper production technology procedures & DB22/T1501.7-2012 \\
\hline DB22/T1501.6-1999 & Pollution-free agricultural products plastic greenhouse eggplant production technology procedures & DB22/T1501.6-2012 \\
\hline JB/T10288-2001 & The structure of greenhouse & JB/T10288-2013 \\
\hline JB/T10286-2001 & The structure of Solar Greenhouse & JB/T10286-2013 \\
\hline JB/T10296-2001 & The greenhouse electrical wiring design specification & JB/T10296-2013 \\
\hline JB/T10297-2001 & The greenhouse heating system design specification & JB/T10297-2014 \\
\hline JB/T10306-2001 & The greenhouse control system design specification & JB/T10306-2013 \\
\hline WB/T1012-2000 & Magnesium Composites agricultural greenhouses & WB/T1012-2012 \\
\hline GB/T19165-2003 & Solar greenhouse and plastic canopy structure and performance requirements & JB/T10594-2006 \\
\hline GB/T19561-2004 & Cold to energy-saving solar greenhouse construction procedures & JB/T10595-2006 \\
\hline DB62/T1434-2006 & Pollution-free vegetables greenhouse tomato cultivation techniques of Qingyang city procedures & DB62/T1434-2012 \\
\hline DB62/T1435-2006 & Pollution-free vegetables greenhouse cucumber cultivation technique of Qingyang city procedures & N/A \\
\hline DB62/T1436-2006 & Pollution-free vegetables greenhouse pepper cultivation techniques of Qingyang city procedures & DB62/T1436-2012 \\
\hline DB32/T1589-2010 & Sushi solar greenhouse (steel) general technical requirements & DB32/T1589-2013 \\
\hline
\end{tabular}

\section{Discussion}

\subsection{Deficiency for greenhouse standardization}

\subsubsection{Degree of standardization}

As is shown in Table 1, the standardized coefficient of multi-span greenhouse parts is obviously higher than the other two types of greenhouse. Multi-span greenhouse technology is introduced from Netherlands. The typical structure of this type is Venlo greenhouse. The standardized coefficient of it is $98.96 \%$ $\left(K_{j}\right)$ and $98.67 \%\left(R_{j}\right)$. The one of tunnel greenhouse is $52.03 \%\left(K_{j}\right)$ and $41.55 \%\left(R_{j}\right)$. The coefficients of solar greenhouse are $78.33 \%$ $\left(K_{j}\right)$ and $28.12 \%\left(R_{j}\right)$. The similar parameters of tunnel greenhouse and solar greenhouse are far below that of Venlo greenhouse. Design standards and construction standards of
Venlo type are referenced and partly referenced directly by foreign relevant standards. The tunnel greenhouse and solar greenhouse have just begun to upgrade the technology of mature building steel structure. So the standard coefficient of the former two greenhouses is lower than that of multi-span greenhouse. In addition, the low standardized coefficients of these two greenhouses have a deep relation to that they depend on the surface parameters of the components with the lack of standardized constraints.

\subsubsection{Standardization system}

The related standards should be established in every link of a continuous process of greenhouse industry that includes antenatal facilities construction, breeding to the production process, postpartum product packaging sales and so on. Range from 2008 
to 2015 , about $67 \%$ of additional standards aimed at solar greenhouse (as shown in Figure 3a), and among the additional standards, $73 \%$ belong to the field of production process technology (as shown in Figure 3c). This standardization development model due to the popularization rate of solar greenhouse is higher than that of another two types. This effect has been accumulated year by year. As shown in Figure 4a, more than $61 \%$ of the standards are concentrated in the field of greenhouse production management in plastic tunnel greenhouse and solar greenhouse. This is due partly to that the highly standardized multi-span greenhouse enhance the general level of each technical content related standards, especially the production process standards. And the standards for auxiliary facilities and production process of another two greenhouse type should be change to suit complicated structure standard system. The standards for auxiliary facilities occupy a large proportion in general technique field. The reason lead to this is some auxiliary facilities used in plastic tunnel greenhouse and solar greenhouse referenced that in multi-span ones. The functions and structures of these facilities are also optimized in order to adapt to the new use environments. The related standards also need to be referenced, adapted, or written. The superposition effect of the variety of the greenhouse structure and greenhouse equipment magnified the demand for greenhouse standards. As a result, the system of the greenhouse standardization in our country is not perfect enough, and cannot meet the need of actual production situation.

\subsubsection{Standard update speed}

Greenhouse standardization had a significant development in China in 2007 and then had sustained growth with the implementation of the 2008 national policies, but due to a late start, the overall standardization is still in slower progress. And the traditional monomer tunnel, solar greenhouse and imported in the greenhouse and other special structure of sightseeing greenhouse exist in this country leads to the satiation that greenhouse standardization work should include modifying the original standard of greenhouse and digesting new technologies after the introduction of new standards at the same time. The target of greenhouse standardizing management in our country at present is still in focus on the greenhouse cultivation standards with the introduction of new technology adaptability. Greenhouse structure and material standards are made in 2007 and former is still in use instead of being updated with the general development of related technologies and materials as of March 2016. In several years, there were only about 17 relative standard were abolished, as shown in Table 2 .

Along with our country constantly into the global integration, greenhouse industry development can not only lock in the domestic technology level, also not only confined to the domestic market. It will make the development of greenhouse products in China faces enormous challenges with the gap exist in between greenhouse standard update speed; the management way developed countries between domestic and overseas.

\subsubsection{Standard generality}

The Figure 4a reveals the proportion of general technique to the whole greenhouse standardization system, it is only about $5.6 \%$, and the general parts belong to production process field accounts for $0.31 \%$ of the whole general production process standards. The remainder is targeted at tunnel greenhouse $(33.33 \%)$ and solar greenhouse $(66.04 \%)$ respectively. The traditional greenhouse in China mainly includes monomer tunnel and solar greenhouse which adapt itself to demand of greenhouse that contains small, short use cycle and low cost. The constructions of monomer tunnel and solar greenhouse have less technical requirements. The technical level of technical person work in greenhouse enterprise is poor, and they are short of awareness and demand for standardization establishment and execution. The local climate and planting habits lead to the different structure of greenhouse have different requirements. Though the content of country or industry standard is made complex to meet that needs, it cannot fit the conditions for that everywhere the greenhouse used or production. Enterprise has the rich experience that how to design greenhouse construction scheme according to the different conditions and characteristics, therefore their performing intention of the standard is passive. The communications of technical specifications between enterprises are mainly by imitating products of each other and more technical personnel flow. Form a guild regulation in the form of experience, rather than summarize and implement corresponding standards. This brings about the hindrances of standard use and develops in the company.

Although agricultural land use is relatively flexible with the national land policy adjustment, the customize demand of greenhouse construction led by the independent production of greenhouse users is so bigger that there is no unified management. This makes greenhouse systematized design, production, inspection, the packaging is relatively difficult to be achieved, and influence the development of standardization farther.

\subsubsection{Enterprise participation}

Enterprise standard belongs to individual standard category. It is only set by the production requirements and conditions of the enterprise $^{[39]}$. Enterprise standards can play a good complement to the details of the greenhouse standard system. Mature high-level standards require a certain number of low level technical standards support. Based on the above points, the standard is in the Pyramid distribution at the field of national, industry, local and enterprise level. However, as shown in Figures $3 b$ and $4 b$, the proportion of enterprise standards is less than $1 \%$ in the current greenhouse standard system. Their participation is lower than other standardized organizations for two primary reasons. One is that very few self-organized standardization organizations exist, since association standardization has just started in China. The second reason for China's low number of nongovernment standardization organizations is simply its development history. That means there were short amount of time these groups have had to grow ${ }^{[22]}$.

\subsection{Countermeasures for the further development}

\subsubsection{Rational planning of greenhouse standard system}

Greenhouse standard formulation and implementation is a lack of a plan as a whole in our country, this has led to that the standard content is relatively concentrated and technical standard system is not integrated. So aiming at completing the greenhouse standard system, the development of it should be guided by coordination of regulation policy and market competition to improve the lag link of standard and the lack of technology node. The standard formulation agencies or organizations should be directed to focus on the development of greenhouse standards of prenatal and postnatal related tech on the basis of the abundant technical standards and technical details about greenhouse industry. For the newly introduced technology of greenhouse that is in the popularizing phase, such as the multi-span greenhouse, the appropriate standard is supposed to established and promoted by means of referencing to the corresponding standard and combining 
with the actual situation. In order to avoid cross and duplication of the technology tree, technical requirements of different greenhouse related standards ought to be unified for the diversity and complexity of the greenhouse itself ${ }^{[40-42]}$.

5.2.2 The standards need to be updated iteratively

Greenhouse standard should be updated with the continuous change of greenhouse performance and extreme use conditions. The technical committee of EU will upgrade the standard with variations specific to the particular requirements of greenhouses and in particular, requires that glasshouses be designed to serviceability limit states and flexible clad structures (such as poly-tunnels) be designed to ultimate limit states only ${ }^{[43]}$. At present, the development of the standard presents the policy trend that the explosive growth of it is always followed by encouraging policy, but the lack of attention and maintenance will be along with the end of the encouraging and promoting phase of policies. This will lead to the situation that the lifespan of a standard is not reasonable. For this phenomenon, the activity of development institutions for sharing technical achievements and participating in completing standard should be improved by guaranteeing profit for technology holders during technology transfer process in the way that patent transfer and standards license both of which mainly depend on the perfect protection mechanism of high and new technology. Relying on this pattern, new technology research and development institutions will be stimulated to update greenhouse standard iteratively in the cycle of producing new standard from new technology, and then using new profit standards feedback new technology research and development of a benign ${ }^{[44,45]}$.

\subsubsection{Encourage enterprises to participate in standardization}

The enterprises which participate in greenhouse production and services should establish enterprise standardization mechanism which can make them be able to promote technological progress and adapt to market competition needs. According to the technological progress and the need for production and operation target, the technical standards as the main body and enterprise standard system that includes the management standards and working standards should be established and improved. In addition, it should keep advantage and applicability through following the demand of the user and the market closely. Through the commercial competition of enterprises, the corresponding standard competition is promoted. And in this way, the standards representing different technical levels and fields are merged, upgraded or eliminated. Non-governmental standardization associations, alliances, and other organizations are a major power driving the development of association standards in China. The government should carry out reforms to make it easier for private enterprises to jointly establish nonprofit institutions and, in particular, to ease the limitations on nongovernmental parties establishing industry standardization associations ${ }^{[22]}$. For enterprises, gaining standard discourse power can increase the competitiveness of their greenhouse products or services industry organizations, research institutions and academic groups and related standardization professional organizations should use their own advantages to promote standard implementation actively with enterprises $^{[46,47]}$

\section{Conclusions}

The greenhouse standards are in the stage of stable development in China, and the greenhouse standard system has been becoming perfect. But the development of standard system also has some problems, such as uneven distribution of technical content in greenhouse related standards; the uncertainty of the technology system leads to the problem of focusing on the creation of the redundancy standard rather than the optimization of the basic standards; and the participation of enterprises is not extremely enough. According to the problems above, this paper puts forward corresponding countermeasures to improve development speed and quality of greenhouse standard system and then improve the influence and competitiveness of the greenhouse industry in China.

\section{Acknowledgement}

This work was supported by National Key Technology R\&D Program of China during the 12th Five-Year Plan Period (Grant No. 2012BAD35B02).

\section{[References]}

[1] Chen Y, Shi Y L, Wang Z Y, Huang L. Connectivity of wireless sensor networks for plant growth in greenhouse. Int J Agric \& Biol Eng, 2016; 9(1): 89-98.

[2] Yang Q H, Feng B L. Development status and countermeasures of facility agriculture standardization. The Opportunity of Standardization Reform and Development: The 12th China Standardization Forum, Zhejiang, Hangzhou, China, 2015.

[3] Vieira Neto J G, Soriano J, Vieira Neto J G, Soriano J. Distribution of stress in greenhouses frames estimated by aerodynamic coefficients of Brazilian and European standards. Sci. Agric, 2016; 73(2): 97-102.

[4] Roux P, Gratraud J. Standards for greenhouses construction in France and structure calculation according to standards. Acta Horticulturae, 1990; 281: 139-148.

[5] Bijlaard F S K. CEN - Standard for design of greenhouses. REUR Technical Series, 1992; 25: 122-128.

[6] Waaijenberg D. Design, construction and maintenance of greenhouse structures. Acta Horticulturae, 2006; 710(710): 31-42.

[7] Vassiliou N N. Greenhouse standards from the financial institutions and insurance companies point of view. REUR Technical Series, 1992; 25: 114-121.

[8] Zhang Z, Gates R S, Zou Z R, Hu X H. Evaluation of ventilation performance and energy efficiency of greenhouse fans. International Journal of Agricultural \& Biological Engineering, 2015; 8(1): 103-110.

[9] Tagliafico A, Tagliafico G, Houssami N. Actual greenhouses and tunnels. Structures and protective implements. British Journal of Radiology, 2013; 86(1032): 196-209.

[10] Wei X M, Li M, Zhou C J. Comparison of snow load distribution coefficients in plastic greenhouse in different countries. Journal of Agricultural Mechanization Research, 2014; 1: 51-55. (in Chinese)

[11] Xu L L, Zhou C J, Zhao Y L, Li S J. Investigation and thinking of greenhouse construction standardization development in Shouguang. Tianjin Agricultural Sciences, 2014; 12: 113-117. (in Chinese)

[12] Freeman S, Gnayem N. Use of plasticulture for strawberry plant production. Small Fruits Review, 2005; 4(1): 21-32.

[13] Lewers K S, Fleisher D H, Daughtry C S T. Low tunnels as a strawberry breeding tool and season-extending production system. International Journal of Fruit Science, 2017; 17(3): 1-26.

[14] Qi F, Tong G S. Stability design methods for steel frame of agricultural gutter-connected greenhouse. Transactions of the CSAE, 2009; 25(9): 202-209. (in Chinese)

[15] Castilla N. Greenhouse technology and management. Ebooks on agriculture and the applied life sciences from CAB International, 2013. DOI: 10.1079/9781780641034. 0000.

[16] von Elsner B, Briassoulis D, Waaijenberg D, Mistriotis A, von Zabeltitz C, Gratraud J, et al. Review of structural and functional characteristics of greenhouses in European Union countries, part II: Typical designs. Journal of Agricultural Engineering Research, 2000; 75(2): 111-126.

[17] Elsner B V, Briassoulis D, Waaijenberg D, Mistriotis A, von Zabeltitz C, Gratraud J, et al. Review of structural and functional characteristics of greenhouses in European Union countries: Part I, design requirements. Journal of Agricultural Engineering Research, 2000; 75(1): 1-16.

[18] Li Y, Li B, Wang C, Shi Y. Effects of shading and roof sprinkling in Venlo-type greenhouse in summer. Transactions of the CSAE, 2002; 18(5): 127-130. (in Chinese) 
[19] Nelson P V. Greenhouse operation and management. Prentice Hall, 1998. ISBN-10: 0132439360.

[20] Zhang L Y. Analysis on the steel frame structure of multi-span plastic greenhouse in north China. Master thesis. Shandong Agricultural University, 2008. (in Chinese)

[21] Ding X, Zhou C. Test and measurement of solar visible radiation transmittance of greenhouse glazing. Transactions of the CSAE, 2008; 24(8): 210-213. (in Chinese)

[22] Liu H, Cargill C F. Setting standards for industry: Comparing the emerging Chinese standardization system and the current US system, 2017.

[23] Tian H Q, Guo Y M. Calculation of load analysis and structure optimization of northern greenhouse. Contemporary Farm Machinery, 2007; 2 : 56-57.

[24] Zhao L Z. Applied research on the design of greenhouse based on modularization. Zhejiang University of Technology, 2008. (in Chinese)

[25] Shi Y. Analysis and application of "Jizi" cold-formed steel in the greenhouse structure. Kunming University of Science and Technology, 2012. (in Chinese)

[26] Shi Y, Fan J. Cold-formed "Jizi" steel and traditional square steel in greenhouse structure application in finite element analysis. Science Technology and Engineering, 2012; 12(15): 3653-3656.

[27] Zhao J G, Wang N, Ding Y Q. Discussion on calculation method of standardized coefficient of construction machinery products. Construction Machinery \& Maintenance, 2015; S1: 78-83. (in Chinese)

[28] Ding C. Ding C. To analyze the development actuality of cold-formed thin-walled light-steel members in the world. Steel Construction, 2003; 6. (in Chinese)

[29] Qiu G Y, Sase S, Isobe S, Okushima L. An overview of the latest greenhouse industry in China. Journal of Agricultural Meteorology, 2010; 54(54): 167-170.

[30] Lian J K. Classification of greenhouse. Agricultural Engineering Technology, 2007; 7: 23-24. (in Chinese)

[31] Hemant U, Singh A, Ahlawat T. Standardization of dehydration technique for greenhouse cut rose var. Shakira. Indian Journal of Horticulture, 2016; 73(1): 99.

[32] Franco-Hermida J J, Quintero M F, Cabrera R I, Guzmán M. Determination of diagnostic standards on saturated soil extracts for cut roses grown in greenhouses. Plos One, 2017; 12(5): e0178500.

[33] Wu B L, Xu Z H, Zhang C H, Shou W S, Dong W Q, Lei J L. Structure, environment characteristics and application effect of southern-type solar greenhouse. Acta Agriculturae Zhejiangensis, 2010; 22(6): 848-853.

[34] Liu J, Pang Z. Analysis and suggestions on standardization of facility agricultural engineering in Hainan. Tropical Agricultural Engineering, 2014. (in Chinese)

[35] Dova E, Katsoulas N, Kittas C, Sophianopoulos D. Differences in required structural efficiency of standard commercial steel greenhouses among EU countries: a Hellenic experience. Acta Horticulturae, 2012; 927(927): 695-701.

[36] Cao X W, Wu T L, Shi H F, Xiao L G. Discussion on standardized design of greenhouse structure in Holland, Agricultural Mechanization in Xinjiang, 2015; 3: 36-38. (in Chinese)

[37] Solieri L. The European standard for greenhouses. Pt.1 CEN, European Committee for Standardization. Colture Protette, 2005.
[38] Qi F. Features of load effects and application in designing Venlo greenhouse. Transactions of the CSAE, 2007; 23(3): 163-168. (in Chinese)

[39] Zhang S W. Research on the adaptive mechanism and empirical study of technology standardization and technological development level. Master thesis, Jilin University, 2015. (in Chinese)

[40] Gómez-López V M, Bolton J R. An approach to standardize methods for fluence determination in bench-scale pulsed light experiments. Food \& Bioprocess Technology, 2016; 9(6): 1040-1048

[41] Fang C L, Sa L M, Wang X S. Standardize methods for formulation of science and technology development plan to support CNPC's science and technology development plan in 13th five-year plan period. Oil Forum, 2014; 33(6): 1-5. (in Chinese)

[42] Polanczyk A, Podyma M, Trebinski L, Chrzastek J, Zbicinski I, Stefanczyk L. A novel attempt to standardize results of CFD simulations basing on spatial configuration of aortic stent-grafts. PLoS One, 2016; 11(4)

[43] Budd C A. New European standard for the design and construction of greenhouses. Acta Horticulturae, 1997; (443): 93-98.

[44] á Torkilsheyggi A. Flexibility first, then standardize: A strategy for growing inter-departmental systems. Studies in Health Technology \& Informatics, 2015; 216: 477-481.

[45] Lim C-K, Tang C-S, Hsao W-Y, Hou J-H, Liu Y-T. New media in digital design process: Towards a standardize procedure of CAD/CAM fabrication. Proceedings of the 11th International Conference on Computer Aided Architectural Design Research, Asia Kumamoto, Japan, March 30th - April 2nd, 2006; pp.597-599.

[46] Cogin J A, Williamson I O. Standardize or customize: The interactive effects of HRM and environment uncertainty on MNC subsidiary performance. Human Resource Management, 2014; 53(5): 701-721.

[47] Zhang Y. Approach to standardize power configuration in unitary system. Journal of Jiangsu Administration Institute, 2012. (in Chinese)

[48] Liu Y F. Wind resistant performance analysis and structural parameter optimization of truss arch light steel plastic greenhouse. Heilongjiang Bayi Agricultural University, 2017. (in Chinese)

[49] Yang Q H, Feng B. Facilities agricultural standardization development present situation and the countermeasures: Opportunities for reform of standardization and development. The 12th China Standardization BBS, China, 2015. (in Chinese)

[50] National G M A. Standards for ventilating and cooling greenhouses. Florists Exchange, 1962; 138(2-4): 16-17, 20-21.

[51] Pan R N. Standardized coefficient of design finalization for ship type. Ship Standardization Engineer, 2017; 50(3): 7-10. (in Chinese)

[52] Kurztusch H, Nagel L. Control equipment a standard solution for the automatic sprinkling in greenhouses. Technische Information GRW. 1978; 16: 22-24.

[53] Won C, Jeongjae L, Seongsoo Y. Regular truss structure model equivalent to continuum structure. Int J Agric \& Biol Eng, 2015; 8(5): 151-161.

[54] Ha T, Lee I B, Kwon K S, Hong S W. Computation and field experiment validation of greenhouse energy load using Building Energy Simulation model. Int J Agric \& Biol Eng, 2015; 8(6): 116-127.

[55] Flores-Velazquez J, Montero J I, Baeza E J, Lopez J C. Mechanical and natural ventilation systems in a greenhouse designed using computational fluid dynamics. Int J Agric \& Biol Eng, 2014; 7(1): 1-16. 